\title{
The Actual Status of Elderly Orofacial-Function Improvement Program in Seoul and Gyenggi-Area
}

\author{
Do-Seon Lim*, Ju-hee Kim*, So-yeon Lee, and Im-Hee Jung ${ }^{\dagger}$ \\ Department of Dental Hygiene, Eulji University, Seongnam 13135, Korea
}

\begin{abstract}
Background: Although the orofacial-function improvement exercise (OFIE; oral exercise) was first introduced in Korea 10 years prior, it is still not covered by medical insurance, and no detailed survey on the dissemination of related programs has been conducted. Therefore, this study investigated the actual status of the education and practice of OFIE among the elderly and at elderly welfare institutions in the Seoul and Gyeonggi Provinces.

Methods: Senior citizens aged more than 65 years old, public health centers (total of 69) and elderly welfare institutions (including nursing homes and elderly welfare centers, total of 56) per administrative area in the Seoul and Gyeonggi Provinces were targeted. We analyzed 200 elderly people and 93 institutions who agreed to participate in the survey. For the elderly, general characteristics, experience and route, current practice, and necessity regarding OFIE were investigated. For institutions, the history and plan of education programs on OFIE were investigated.

Results: Regardless of the general characteristics, both the rate of experience and practice for OFIE were low overall; moreover, although they felt it was necessary, they had insufficient motivation for its implementation. Moreover, only a few institutions which were operating the education about OFIE regardless of the COVID-19 situation.

Conclusion: Although OFIE is necessary for the elderly, its distribution remains insufficient. Therefore, further efforts are needed to expand the education and raise the awareness of oral exercise among elderly individuals and senior welfare institutions.
\end{abstract}

Key Words: Community health services, Dental care for aged, Educational status, Orofacial myotherapy, Private practice

\section{Introduction}

Physical heath is crucial to ensuring a high quality of life among older adults. Oral health is especially important for older adults, as it serves essential functions for sustaining life and carrying on social lives, including mastication, swallowing, and pronunciation ${ }^{1,2)}$. However, older adults encounter a variety of oral health problems due to aging and other reasons. According to a previous study, more than $41 \%$ of older adults in Korea are suffering from chewing discomfort ${ }^{3)}$, and more than $70 \%$ of those aged 55 years and over in Korea have dry mouth-related symptoms, $25.8 \%$ of whom clearly are diagnosed as dry mouth ${ }^{4}$. Dry mouth not only causes pain, alters taste, and diminishes the self-cleansing action, but also leads to food intake and pronunciation difficulties. It may also lower older adults' overall quality of life by four folds ${ }^{5)}$, and chewing and swallowing difficulties may increase the risk for nutritional deficiency, frailty, and even mortality ${ }^{6)}$.

To resolve oral dysfunctions in older adults, Hwang and $\mathrm{Cho}^{7)}$ introduced the "orofacial-function improvement exercise (OFIE; oral exercise)" launched by a public health center in the city of Kochi, Japan, in Korea in 2009. This oral exercise regimen 10 sets of oral exercises that target to enhance oral functions: warm-up (deep breathing, neck and shoulder stretching), mouth opening and tongue stretching (strengthen masseter, temporalis, and tongue 
muscles), cheek and neck stretching (strengthen masseter, temporal, buccinator, platysma, and orbicular oris muscles), tongue exercise (increase tongue muscle strength and stimulate salivary glands), masticatory exercise (strengthen muscles of mastication), inflating cheeks with air (strengthen orbicularis oris), swallowing exercise (enhance swallowing motion), articulation exercise (linguolabial articulation exercise, involving tongue, lip, and soft palate), cool-down (breathing). The goals of oral exercise are to prevent oral dysfunctions in healthy older adults and to facilitate functional recovery and maintenance in older adults with oral dysfunction by continuously moving and training various oral tissues, and its effectiveness has been documented in several studies ${ }^{8-14)}$. After participating in an oral exercise program, older adults showed better perceived mouth dryness by 20.91 points $^{8)}$, an increase of unstimulated salivary flow rate by 0.029 to $0.1 \mathrm{ml} / \mathrm{min}^{8-12}$, maximum mouth opening by 0.2 to $0.4 \mathrm{~cm}^{9,11,12)}$, mouth inflating by $22.6 \%{ }^{13)}$, and articulation by 0.04 to 8.36 times ${ }^{9,11-14)}$, showing that all relevant oral functions were significantly enhanced. Moreover, anticipated popularity and satisfaction regarding oral exercise programs were high, so launching them as national health projects would help effectively promote elderly health ${ }^{9)}$.

In response to the super-aging of population, the Japanese government launched these oral intervention programs for its people through national social insurance (preventive long-term care project) since 2006 and has run these programs as facility-based community support project for all older adults, including active older adults ${ }^{15)}$. In Korea, long-term care insurance is a similar system for older adults. The facility-based community support project comprises oral functional enhancement programs, exercise programs, and nutritional enhancement programs, but in 2018 , the project was updated so the programs are also covered as home-based support services ${ }^{16)}$. In Korea, free oral services provided for older adults as of 2021 are fluoride application and scaling through the Integrated Health Promotion Project ${ }^{17)}$, and dentures (once/7 years) and dental implants (two/lifetime) through the Medicaid system $^{18)}$. Despite implementing the program in Korea under the title "oral exercise" in 2009, relevant oral health project's and policies are still lacking even after 10 years.
Moreover, no study in the past has surveyed the level of awareness of oral exercise, current practice of oral exercise, or the implementation of relevant education among older adults in Korea. Rapid popularization of oral exercises would require an understanding of the status quo, which would also contribute to determining the directions of future education and policies.

In this context, this study aims to investigate the oral exercise exposure rate and implementation rate among older adults aged 65 years and over and oral exercise training programs in public health centers and senior welfare centers by region in Seoul and Gyeonggi Provinces, which feature a relatively high number of residential welfare facilities for older adults.

\section{Materials and Methods}

\section{Study population}

The study population was set to older adults aged 65 years and over in Seoul or Gyeonggi Province as well as public health centers in these two regions (69 centers) and one senior welfare facility (e.g., nursing home, senior welfare center) for each administrative district (56 facilities). After excluding careless responses, data from 200 older adults and 93 consenting facilities were included in the analysis.

\section{Instruments}

The questionnaire was taken from the tools developed by Hwang and $\mathrm{Cho}^{7)}$ and $\mathrm{Kim}^{19)}$, with some modifications and adaptation to collect information about participants' general characteristics and oral exercise. The questionnaire for older adults consisted of three items for general characteristics and 11 items for oral exercise (prior exposure, channel of exposure, practice, and need), and the questionnaire for facilities consisted of one general characteristic and 10 items for oral exercise (running experience of oral exercise training program, form of program, and future plan). The reliability (Cronbach's $\alpha$ ) of the questionnaires was 0.852 for the questionnaire for older adults and 0.665 for the questionnaire for facilities. 


\section{Method}

A self-report questionnaire was administered from April 8, 2021 to April 27, 2021. For the survey of older adults, we visited the convenience-sampled regions in Seoul and Gyeonggi Provinces and obtained a informed consent from the recruited older adult participants before administering the questionnaire. For the survey of facilities, we called the public health centers and senior welfare facilities in each of the regions to ask for participation and delivered the questionnaires to the facilities that provided consent to participate. Prior to both surveys, we provided an explanation about oral exercise using pictures and videos.

\section{Data analysis}

Data on older adults' and facilities' general characteristics and current status were analyzed with frequency analysis. The differences in oral exercise exposure rate and practice rate according to older adults' general characteristics were analyzed with chi-squared test, and the differences in the need for oral exercise according to general characteristics were analyzed with Kruskal-Wallis test and Mann-Whitney test. Statistical analyses were performed using the SPSS (ver 26.0; IBM Corp., Armonk, NY, USA) software, at a confidence level of $95 \%(p<0.05)$.

\section{Results}

\section{Oral exercise trends in older adults aged 65 years and over in Seoul and Gyeonggi}

\section{1) Oral exercise exposure, practice, and need according to general characteristics in older adults}

Table 1 shows the oral exercise exposure rate, current practice rate, and oral exercise needs among 200 older adults in Seoul and Gyeonggi regions.

There were $111(55.5 \%)$ females and 89 (44.5\%) males. The predominant age group was 70 to 79 years $(n=80$, $40 \%$ ), followed by 65 to 69 years ( $n=68,34.0 \%), 80$ to 89 years $(n=49,24.5 \%)$, and $\geq 90$ years $(n=3,1.5 \%)$. The most common number of medications currently taken was 1 to $2(n=96,48.0 \%)$, followed by $0(n=45,22.5 \%), 3$ to 4 $(\mathrm{n}=45,22.5 \%)$, and $\geq 5(\mathrm{n}=14,7.0 \%)$.

Regarding prior exposure to oral exercise (e.g., training, trial), 139 (69.5\%) had no exposure, while 61 (30.5\%) had exposure, showing that more than half of the participants did not have been exposed to oral exercise. Regarding current practice of oral exercise, the majority of the participants $(\mathrm{n}=165,82.5 \%)$ were not currently practicing oral exercise, while $33(16.5 \%)$ and $2(1.0 \%)$ participants

Table 1. The Status of Experience, Practice, and Need of Orofacial-Function Improvement Exercise according to General Characteristics

\begin{tabular}{|c|c|c|c|c|c|c|c|c|c|c|}
\hline \multirow[b]{2}{*}{ Variable } & \multirow{2}{*}{$\begin{array}{l}\text { Number of } \\
\text { participants }\end{array}$} & \multicolumn{3}{|c|}{ Experience $^{\mathrm{a}}$} & \multicolumn{4}{|c|}{ Current practice $^{\mathrm{a}}$} & \multicolumn{2}{|c|}{ Need (5 point scale) } \\
\hline & & Yes & No & p-value & $\begin{array}{l}\text { Exercise } \\
\text { all }\end{array}$ & $\begin{array}{c}\text { Exercise } \\
\text { some parts }\end{array}$ & $\begin{array}{c}\text { Do not } \\
\text { exercise at all }\end{array}$ & p-value & Point & p-value \\
\hline Sex & & & & 0.566 & & & & 0.444 & & 0.848 \\
\hline Male & $89(44.5)$ & $29(47.5)$ & $60(43.2)$ & & $0(0.0)$ & $15(45.5)$ & $74(44.8)$ & & $2.69 \pm 1.018$ & \\
\hline Female & $111(55.5)$ & $32(52.5)$ & $79(56.8)$ & & $2(100)$ & $18(54.5)$ & $91(55.2)$ & & $2.69 \pm 0.932$ & \\
\hline Age (y) & & & & 0.975 & & & & 0.919 & & 0.011 \\
\hline $65 \sim 69$ & $68(34.0)$ & $22(36.1)$ & $46(33.1)$ & & $1(50.0)$ & $9(27.3)$ & $58(35.2)$ & & $2.68 \pm 0.921$ & \\
\hline $70 \sim 79$ & $80(40.0)$ & $24(39.3)$ & $56(40.3)$ & & $1(50.0)$ & $14(42.4)$ & $65(39.4)$ & & $2.53 \pm 0.856$ & \\
\hline $80 \sim 89$ & $49(24.5)$ & $14(23.0)$ & $35(25.2)$ & & $0(0.0)$ & $9(27.3)$ & $40(24.2)$ & & $2.86 \pm 1.080$ & \\
\hline$\geq 90$ & $3(1.5)$ & $1(1.6)$ & $2(1.4)$ & & $0(0.0)$ & $1(3.0)$ & $2(1.2)$ & & $4.67 \pm 0.577$ & \\
\hline \multicolumn{4}{|c|}{ The number of medication you are taking } & 0.603 & & & & 0.435 & & 0.884 \\
\hline None & $45(22.5)$ & $11(18.0)$ & $34(24.5)$ & & $1(50.0)$ & $3(9.1)$ & $41(24.8)$ & & $2.71 \pm 0.920$ & \\
\hline $1 \sim 2$ & $96(48.0)$ & $32(52.5)$ & $64(46.0)$ & & $1(50.0)$ & $20(60.6)$ & $75(45.5)$ & & $2.73 \pm 0.968$ & \\
\hline $3 \sim 4$ & $45(22.5)$ & $15(24.6)$ & $30(21.6)$ & & $0(0.0)$ & $7(21.2)$ & $38(23.0)$ & & $2.58 \pm 0.965$ & \\
\hline$\geq 5$ & $14(7.0)$ & $3(4.9)$ & $11(7.9)$ & & $0(0.0)$ & $3(9.1)$ & $11(6.7)$ & & $2.71 \pm 1.204$ & \\
\hline Total & $200(100)$ & $61(100)$ & $139(100)$ & & $2(100)$ & $33(100)$ & $165(100)$ & & $2.69 \pm 0.969$ & \\
\hline
\end{tabular}

Values are presented as number $(\%)$ or mean \pm standard deviation.

${ }^{\mathrm{a}} \mathrm{By}$ chi-square test.

by Mann-Whitney or Kruskal-Wallis test. 
were practicing some exercises and practicing the entire program, respectively. Regarding the perceived need for oral exercise, 87 (43.5\%) said "I need it," followed by "so-so" (n=57, 28.5\%), "I don't need it" ( $\mathrm{n}=35,17.5 \%)$, "I need it a lot" $(\mathrm{n}=13,6.5 \%)$, and "I don't need it at all" $(\mathrm{n}=8,4.0 \%)$.

There were no statistically significant differences in the oral exercise exposure and practice according to sex, age, and number of medications. On the other hand, there were statistically significant differences in the needs for oral exercise according to age, where the $\geq 80$ years group had high perceived need $(p<0.05)$. However, it was not significantly associated with sex and number of medications.

\section{2) Channel of oral exercise exposure, weekly frequency, and reason for non-practice in older adults}

Table 2 shows the channels of oral exercise exposure, weekly frequency, and reason for non-practice in older adults.

We additionally asked about prior training and route of exposure among participants who claimed to have been exposed to oral exercise, such as through training and trials. The most common channel of exposure was TV $(\mathrm{n}=25,12.5 \%)$, followed by senior welfare facilities $(\mathrm{n}=18,9.0 \%)$, dental clinic $(\mathrm{n}=7,3.5 \%)$, acquaintance

Table 2. The Education Channel and Number of Exercises per Week for Orofacial-function Improvement Exercise

\begin{tabular}{lc}
\multicolumn{1}{c}{ Variable } & Value \\
\hline Eduction channel & \\
Dental clinic & $7(3.5)$ \\
Care centers for senior & $18(9.0)$ \\
Commnunity healthcare center & $3(1.5)$ \\
TV & $25(12.5)$ \\
Internet & $3(1.5)$ \\
Acquaintance & $4(2.0)$ \\
Others & $1(0.5)$ \\
None (have no experience) & $139(69.5)$ \\
The number of exercise per week & \\
None & $165(82.5)$ \\
1 time & $19(9.5)$ \\
2 times & $6(3.0)$ \\
More than 3 times & $10(5.0)$ \\
Total & $200(100)$ \\
\hline
\end{tabular}

Values are presented as number (\%). $(\mathrm{n}=4,2.0 \%)$, community public healthcare center $(\mathrm{n}=3$, $1.5 \%)$, and internet $(\mathrm{n}=3,1.5 \%)$. After excluding individuals who do not currently practice oral exercise, the weekly frequency of exercise was once a week $(\mathrm{n}=19,9.5 \%), \geq 3$ times a week $(\mathrm{n}=10,5.0 \%)$, and twice a week $(\mathrm{n}=6,3.0 \%)$.

We asked about the reasons for not practicing oral exercise to those who claimed to be not practicing oral exercise. The most common reason was "never heard of it" ( $\mathrm{n}=126,63.0 \%)$, followed by "never been properly trained" ( $\mathrm{n}=33,16.5 \%)$, "Learned about it but can't remember the correct order or method" $(\mathrm{n}=22,11.0 \%)$, "don't feel like it" ( $\mathrm{n}=17,8.5 \%)$, "not interested" $(\mathrm{n}=16$, $8.0 \%)$, "don't see its benefits over other exercises" ( $\mathrm{n}=11$, $5.5 \%$ ), "difficult to perform the exercise due to physical challenges" ( $n=6,3.0 \%)$, "can try but the exercise is too challenging and tiring" $(\mathrm{n}=4,2.0 \%)$.

\section{Current status of oral exercise training in public health centers and senior welfare facilities in Seoul and Gyeonggi}

\section{1) Types of participating facilities}

Table 3 shows the facilities that participated in the survey. They included community public healthcare centers $(n=36,38.7 \%)$, day-care centers $(n=23,24.7 \%)$, senior welfare centers $(\mathrm{n}=17,18.3 \%)$, and senior care certers $(\mathrm{n}=7,7.5 \%)$. "Other" types of facilities included six home care facilities (home care centers for older adults), one long-term care hospital, one public medical center, one senior day center, and one senior club.

Table 3. The Types of Senior-Care Centers

\begin{tabular}{lc}
\hline \multicolumn{1}{c}{ Variable } & Value \\
\hline The sort of centers & \\
Commnunity healthcare center & $36(38.7)$ \\
Seniors welfare center & $17(18.3)$ \\
Senior care center & $7(7.5)$ \\
Day-care center & $23(24.7)$ \\
Others & $10(10.8)$ \\
Total & $93(100)$ \\
\hline
\end{tabular}

Values are presented as number (\%). 


\section{2) Current status of oral exercise training and need for providing training in public health centers and senior welfare facilities}

Table 4 shows the current status of oral exercise training in 93 public health centers and senior welfare facilities in Seoul and Gyeonggi regions. The majority of the facilities were not currently providing training $(n=68,73.1 \%)$, while $15(16.1 \%)$ and $10(10.8 \%)$ were providing training for some exercises and providing training for the entire program, respectively.

We additionally surveyed the details of training programs among 25 facilities that are currently providing training. Twelve facilities $(48.0 \%)$ were providing training

Table 4. The Status and Opinion of Centers Concerning the Education Programs of Orofacial-Function Improvement Exercise for Senior Individuals

\begin{tabular}{|c|c|}
\hline Variable & Value \\
\hline \multicolumn{2}{|l|}{ Current education } \\
\hline Yes (educating all of the exercise program) & $15(16.1)$ \\
\hline Yes (educating some parts of the exercise program) & $10(10.8)$ \\
\hline No (not educating any of the program) & $68(73.1)$ \\
\hline \multicolumn{2}{|l|}{$\begin{array}{l}\text { For the centers who are operating education program } \\
\text { currently }(n=25)\end{array}$} \\
\hline \multicolumn{2}{|l|}{ Term of education } \\
\hline Regularly & $12(48.0)$ \\
\hline Intermittently & $13(52.0)$ \\
\hline \multicolumn{2}{|l|}{ Length of current education (mo) } \\
\hline Less than 6 & $3(12.0)$ \\
\hline $6 \sim 11$ & $4(16.0)$ \\
\hline $12 \sim 23$ & $8(32.0)$ \\
\hline $24 \sim 35$ & $3(12.0)$ \\
\hline$\geq 36$ & $7(28.0)$ \\
\hline \multicolumn{2}{|l|}{$\begin{array}{l}\text { For the centers who are not operating education } \\
\text { program }(n=68)\end{array}$} \\
\hline \multicolumn{2}{|l|}{ Operation experience } \\
\hline Yes (operated before but not now) & $26(38.2)$ \\
\hline No (did not operate at all) & $42(61.8)$ \\
\hline \multicolumn{2}{|l|}{ Plan of future education } \\
\hline Yes (have a plan) & $46(67.6)$ \\
\hline No (have no plan) & $22(32.4)$ \\
\hline \multicolumn{2}{|l|}{ Center's opinions about education for senior } \\
\hline Absolutely necessary & $21(22.6)$ \\
\hline Necessary a lot & $50(53.8)$ \\
\hline Not sure & $20(21.5)$ \\
\hline Unnecessary & $2(2.2)$ \\
\hline Unnecessary at all & $0(0)$ \\
\hline Total & $93(100)$ \\
\hline
\end{tabular}

Values are presented as number (\%). regularly, while $13(52.0 \%)$ were provided training irregularly. The length of the training was 12 to 23 months $(\mathrm{n}=8,32.0 \%), \geq 36$ months $(\mathrm{n}=7,28.0 \%)$, and 6 to 11 months $(n=4,16.0 \%)$. We also surveyed past training programs and future plans to provide training among 68 facilities that are currently not providing training. Twenty-six facilities $(n=26,38.2 \%)$ had provided training in the past, while 46 facilities $(67.6 \%)$ had plans to provide training for oral exercise in the future.

Additionally, Table 4 shows whether the participating facilities viewed oral exercise training to be necessary for older adults. The most common response was that oral exercise training is "necessary a lot" $(\mathrm{n}=50,53.8 \%)$, followed by "absolutely necessary" ( $n=21,22.6 \%)$, "not sure" $(n=20,21.5 \%)$, and "unnecessary" $(n=2,2.2 \%)$.

\section{Discussion}

Oral exercise is a systematic exercise program to strengthen muscles related to oral functions. It does not require any tools or equipment and thus can be performed at any time. Further, even older adults with limited mobility can practice and train oral exercises because the exercise program does not involve large motions. Various effects of oral exercise have been documented in many previous studies, and these effects include increasing salivary buffering capacity by increasing saliva flow rate, alleviating discomfort by improving dry mouth, improving food swallowing and nutritional state, enhancing pronunciation by helping with mouth opening, and improving facial emotional expressions ${ }^{9-14,19,20)}$. Moreover, oral exercise has been confirmed to be effective not only on healthy older adults but also older adults with dentures and older adults in long-term care ${ }^{13,21)}$. Therefore, popularizing oral exercise among older adults in Korea would be substantially conducive to promoting their oral health in the face of imminent super-aged society. However, no past study has reported the details of oral exercise among older adults in 2021, so we investigated oral exercise exposure/practice among older adults $(\geq 65$ years of age) and oral exercise training programs in public health centers and senior welfare facilities in Seoul and Gyeonggi regions. 
Of 200 older adult participants, 69.5\% $(n=139)$ had no prior exposure to oral exercise, and $82.5 \%(n=165)$ were not currently practicing oral exercise. Moreover, the most common reasons for not practicing oral exercise were not having been properly trained for the exercise or having forgotten about it. In a study on oral health education experiences among older adults aged 65 years and over in Seoul and Gyeonggi, Kim et al. ${ }^{22)}$ reported that $49.1 \%$ $(n=195)$ of 397 participants had been educated about it, $44.1 \%$ of whom were practicing correct tooth brushing techniques and $48.7 \%$ of whom were using oral hygiene products, based on which the authors stated that relevant education and training are essential to promoting practice. Thus, relevant education and training need to be provided to increase older adults' exposure to and practice of oral exercise.

Among 61 (30.5\%) participants who have had oral exercise training, the most common channel of training was TV, followed by senior welfare center, dental clinic, acquaintance, and internet or public health center, with $41.0 \%$ of these participants having learned through TV, and $11.5 \%$ and $4.9 \%$ having learned through a dental clinic and public health center, respectively. According to the previously described study by Kim et al. ${ }^{22)}$, the channels of oral health education among older adults in Seoul and Gyeonggi in 2012 were senior welfare facilities such as senior centers (49.2\%), dental clinics (35.9\%), public health centers $(13.3 \%)$, and schools and other educational facilities (1.0\%). This shows that TV has become a more influential means of oral health education in 2021, and that senior welfare facilities, dental clinics, and public health centers should provide more oral exercise education and training.

Regarding the general characteristics of older adult participants in this study, there were more older adults currently taking medications $(n=155,77.5 \%)$ than those who are not, with most taking 1 to 2 medications (48.0\%). These trends are consistent among the older adult population in Korea. According to the 2020 Survey of Living Conditions and Welfare Needs of Korean Older Persons conducted by the Ministry of Health and Welfare on 10,097 older adults in Korea ${ }^{23)}$, the majority of older adults in Korea took 1 to 2 types of drugs (56.4\%), followed by 3 to 4 types of drugs (21.4\%). An array of drugs, including antihypertensive drugs, diuretics, antidepressants, and anticonvulsants, are reported to reduce salivary flow rate ${ }^{24)}$, and these drugs are frequently utilized on older adults to treat common diseases in the population, such as hypertension, dementia, and musculoskeletal disorders. The use of medications further increases with advancing age and increased prevalence of systemic diseases, and this leads to oral dryness and dry mouth $^{24,25)}$. So et al. ${ }^{4)}$ reported that the prevalence and intensity of dry mouth among older adults increases by 1.59 times with 10-year increase in age, 2.16 times in women, 1.88 times with the number of medications increasing from 1 to 2 , and 2.32 times with the number of medications increasing from 2 to 3 . Thus, the participants of this study may also suffer from oral dryness, and regular practice of oral exercise can prevent and alleviate the condition. Nevertheless, we observed in this study that a high percentage of older adults were not currently practicing oral exercise and have never been exposed to oral exercise regardless of sex, age, and use of medications. Moreover, although the perceived need for oral exercise is anticipated to increase with increasing number of medications used in order to prevent or resolve oral dryness caused by the drugs, the two parameters were not significantly associated, contrary to our expectations. This seems to be attributable to the lack of understanding and awareness of oral exercise.

Among 93 public health centers and senior welfare facilities in Seoul and Gyeonggi, 73.1\% (68 facilities) were currently not offering oral exercise training, and $61.8 \%$ (42 facilities) of them have never offered such program, attesting to the low availability of oral exercise training programs in public health centers and senior welfare facilities in Seoul and Gyeonggi in 2021. We have also surveyed past availability of training programs considering the coronavirus disease 2019 (COVID-19) pandemic in 2021, but the results still show that oral exercise training is not provided adequately, which may be linked to the reason for the non-practice of oral exercise among community-dwelling older adults. Therefore, additional surveys are needed to identify the reasons for the inadequate provision of training, and this issue should 
be resolved by the dental industry. As $76.4 \%$ of the participating facilities stated that oral exercise training is either needed or highly needed, and $67.6 \%$ of facilities that are not currently providing oral exercise training stated that they plan to provide training in the future, showing that supporting these facilities with running oral exercise training programs can adequately promote oral health of community-dwelling older adults. However, there are still many facilities that do not perceive the need to offer oral exercise training, so continued endeavors are needed to increase the awareness of the importance of oral exercise and enhancement of oral functions.

The results of this study showed that both the exposure and practice rates of oral exercise were low, and the motivations for practicing them was low despite perceived need among older adults even though Seoul and Gyeonggi regions are well-equipped with senior welfare facilities. Moreover, not many senior welfare facilities were offering oral exercise programs regardless of the COVID-19 pandemic. Hence, it is essential to develop measures to change the perception about oral exercise, expand training availability, and elevate the practice rate. As this study was only conducted in Seoul and Gyeonggi metropolitan regions and older adults and relevant facilities were conducted with convenient sampling, the findings cannot be generalized nationwide. Further, it was difficult to recruit older adults who have received oral exercise training in the participating facilities due to the COVID-19 pandemic. Thus, we recommend subsequent studies to additionally investigate other regions and concurrently examine facilities that currently offer oral exercise training and their participants.

\section{Notes}

\section{Conflict of interest}

No potential conflict of interest relevant to this article was reported.

\section{Ethical approval}

This study was approved by the Institutional Review Board of Eulji University (IRB No. EU21-007).

\section{Author contributions}

Conceptualization: Im-Hee Jung, Ju-hee Kim, and So-yeon Lee. Data acquisition: Ju-hee Kim and So-yeon Lee. Formal analysis: Ju-hee Kim and So-yeon Lee. Supervision: Im-Hee Jung and Do-Seon Lim. Writingoriginal draft: Im-Hee Jung, Do-Seon Lim, Ju-hee Kim, and So-yeon Lee. Writing-review \& editing: Im-Hee Jung and Do-Seon Lim.

\section{ORCID}

Do-Seon Lim, https://orcid.org/0000-0003-4602-3323

Ju-hee Kim, https://orcid.org/0000-0002-4631-4975

So-yeon Lee, https://orcid.org/0000-0002-1275-039X

Im-Hee Jung, https://orcid.org/0000-0002-8645-1587

\section{Acknowledgements}

This study was supported by research fund from Eulji University, 2021.

\section{References}

1. Nam YS, Jang JY: Potential factors associated with the quality of life in South Korean senior people: based on oral health. J Dent Hyg Sci 13: 281-289, 2013.

2. Yang JM, Song SE, Heo MH, Kim JH: Association between GOHAI (Geriatric Natural Health Assessment Index) and QOL (Quality of Life). Health Soc Welf Rev 40: 245-263, 2020. https://doi.org/10.15709/hswr.2020.40.4.245

3. Kim TH, Jin HJ: Current chewing difficulty according to dental prosthesis needs in Korean elderly. J Korea Acad-Ind Cooper Soc 15: 4353-4360, 2014. https://doi.org/10.5762/KAIS.2014.15.7.4353

4. So JS, Chung SC, Kho HS, Kim YK, Chung JW: Dry mouth among the elderly in Korea: a survey of prevalence, severity, and associated factors. Oral Surg Oral Med Oral Pathol Oral Radiol Endod 110: 475-483, 2010. https://doi.org/10.1016/j.tripleo.2010.05.004

5. Ikebe K, Matsuda K, Morii K, et al.: Impact of dry mouth and hyposalivation on oral health-related quality of life of elderly Japanese. Oral Surg Oral Med Oral Pathol Oral Radiol Endod 103: 216-222, 2007. https://doi.org/10.1016/j.tripleo.2005.12.001

6. Tanaka T, Takahashi K, Hirano H, et al.: Oral frailty as a risk 
factor for physical frailty and mortality in communitydwelling elderly. J Gerontol A Biol Sci Med Sci 73: 1661-1667, 2018. https://doi.org/10.1093/gerona/glx225

7. Hwang YS, Cho EP: A study on elderly people's satisfaction level with oral exercise program. J Korean Acad Dent Hyg Educ 9: 795-807, 2009.

8. Kim YJ, Park KM: Effects on salivation, xerostomia and halitosis in elders after oral function improvement exercises. J Korean Acad Nurs 42: 898-906, 2012. https://doi.org/10.4040/jkan.2012.42.6.898

9. Jang KA, Hwang IC: Objective effects and satisfaction of mouth gymnastics program. J Korea Contents Assoc 11: 388-395, 2011. https://doi.org/10.5392/JKCA.2011.11.10.388

10. Jeon YJ, Choi JS, Han SJ: The effect of dry mouth improvement by oral exercise program in elderly people. J Korean Soc Dent Hyg 12: 293-305, 2012. https://doi.org/10.13065/jksdh.2012.12.2.293

11. Lee SM, Cho EP, Hwang YS, Kang BW: The change of oral function before and after practicing program for oral function improving. J Dent Hyg Sci 11: 497-503, 2011.

12. Jang KA, Hwang IC: Effects of mouth excercise on the improvements of oral function in elderly men. J Dent Hyg Sci 11: 257-263, 2011.

13. Lee JH, Kwon HK, Lee YH, Lee MH, Lee HK: Effect of regular oral exercise on oral function in elderly patients with long-term care. J Korean Acad Oral Health 34: 422-429, 2010.

14. Kim YS, Shin KH, Park JR, Chung SH, Choi HS: The effect of oral function improvement with oral exercise program by elderly people. J Korean Soc Dent Hyg 16: 559-566, 2016. https://doi.org/10.13065/jksdh.2016.16.04.559

15. Sunwoo D: The implications of the Japanese long-term preventive care. Health Welf Policy Forum 131: 97-109,
2007.

16. Kim MJ: A pay-rate increase in Japan's adult social care sector in 2018. Glob Soc Secur Rev 4: 133-142, 2018.

17. Ministry of Health and Welfare: 2020 Guide of integrated health promotion service in communities (oral health). Ministry of Health and Welfare, Sejong, pp.35-58, 2020.

18. Ministry of Health and Welfare: 2021 Guide of medical benefit service. Ministry of Health and Welfare, Sejong, pp.197-212, 2020.

19. Kim DY: Effect of a mouth exercise program on improvement of functions and quality of life related to oral health in the elderly. Unpublished doctoral dissertation, Inje University, Gimhae, 2012.

20. Kim YJ, Choi YH, Kim JY, Lee HK: The effect of orophysical exercise for the elderly on oral function and nutrient intake. J Korean Acad Oral Health 35: 414-422, 2011.

21. Kim JY, Moon WS, Lee KS, Hwang TY: Effects of oral exercise on oral function and denture satisfaction of the elderly. J Agric Med Community Health 40: 158-170, 2015. https://doi.org/10.5393/JAMCH.2015.40.3.158

22. Kim Y, Lee EJ, Kim MK, et al.: A study on the actual conditions of oral health education for the elderly in some communities. J Korean Soc Dent Hyg 12: 921-932, 2012. https://doi.org/10.13065/jksdh.2012.12.5.921

23. Lee YK, Kim SJ, Hwang NH, et al.: 2020 National survey of older Koreans. Korea Institute for Health and Social Affairs, Seoul, pp.261-303, 2020.

24. Ying Joanna ND, Thomson WM: Dry mouth- an overview. Singap Dent J 36: 12-17, 2015. https://doi.org/10.1016/j.sdj.2014.12.001

25. Guggenheimer J, Moore PA: Xerostomia: etiology, recognition and treatment. J Am Dent Assoc 134: 61-99, 2003. https://doi.org/10.14219/jada.archive.2003.0018 